\title{
SARTRE E A QUESTÃO DA MEMÓRIA: ENTRE A RECORDAÇÃO E A ESCOLHA
}

\author{
$\underline{\text { Marcelo Vinicius Miranda Barros }}{ }^{1}$ e Malcom Guimarães Rodrigues ${ }^{2}$ \\ 1. Bolsista PIBIC/FAPESB, Graduando em Psicologia, Universidade Estadual de Feira de Santana, e-mail: \\ marcelovmb@gmail.com \\ 2. Orientador, Departamento de Ciências Humanas e Filosofia, Universidade Estadual de Feira de Santana, e-mail: \\ malcomgr@gmail.com
}

PALAVRAS-CHAVE: Memória; Lembrança; Recordação.

\section{INTRODUÇÃO}

Não é possível considerar que as lembranças surjam de uma instância psicanalítica, como o pré-consciente ou inconsciente (considerando aqui a primeira tópica de Freud, por exemplo), porque todo ser da consciência é consciência de ser, afirma Sartre, suprimindo também a primazia da concepção psicológica de consciência para uma consciência ontológica: o Para-si. Sartre desenvolve suas obras "A imaginação" e "O imaginário" para explicar a possibilidade de termos lembranças sem essa instância psicanalítica ou psicológica. Portanto, quando pensamos em memória não podemos pensar em recordações "dentro" de uma espécie de gaveta (SARTRE, 2012). Em Sartre, o passado do Para-si não pode ser apenas memória. O passado é aquilo que o Para-si foi e, no presente, deve continuar sendo, mas nadificando-se, ou seja, sendo-o à maneira do "era" (SARTRE, 2012). Assim, já que a filosofia de Sartre assume a consciência como princípio e que nada existe dentro da consciência, já que a consciência é sempre consciência de alguma coisa (intencionalidade), ficam as dúvidas: como é possível a imagem na recordação? Se dissermos que a imagem está na experiência de vida, onde está a experiência passada, se a consciência é um nada? Como se posiciona uma lembrança na consciência, de maneira a termos conhecimento dela, se a tal lembrança não está guardada em lugar nenhum, já que não há uma instância psíquica, para Sartre? Se não há um reservatório de lembranças, a lembrança, quando não é conhecimento ou relembrada, fica então não-posicional à consciência reflexiva / conhecimento, então temos para sempre uma intencionalidade da consciência pré-reflexiva tendo como objeto a tal lembrança?

\section{MÉTODO}

Os materiais utilizados foram prioritariamente de ordem textual: livros, artigos, textos etc. A metodologia consistiu, basicamente, em encontros com o orientador, leituras, fichamentos, análises críticas e produção de textos. Os encontros com o orientador e a participação nos grupos de estudo e pesquisa foram fundamentais, especialmente no início da pesquisa, momento no qual as primeiras leituras foram discriminadas e analisadas. Depois das primeiras leituras e fichamentos, a partir de novos encontros com o orientador, passaram à produção do primeiro relatório. Com o avanço da pesquisa, fez parte da metodologia a produção de textos para eventual publicação e a participação em eventos para apresentação dos resultados parciais e/ou finais da pesquisa.

\section{RESULTADOS E/OU DISCUSSÃO}

Sartre questiona a teoria que "busca" algo, em algum "lugar", como sendo recordação. Não há um inconsciente em que a consciência "busque" essas imagens, porque o consciente é intencionalidade sempre: Se toda consciência é consciência de alguma coisa, intencionalidade, "pode-se formar uma consciência por ocasião de um conteúdo sensível, mas não se pode agir pela consciência sobre esse conteúdo sensível, isto é, tirá-lo do nada - ou do inconsciente - ou enviá-lo de volta ao nada" (SARTRE, 2008, p. 108). O Para-si (ou consciência sartreana) não move ou modifica o Em-si (as coisas do mundo), senão, estaria se 
evidenciando um idealismo, que a filosofia sartreana tanto combate. A consciência precisa do fenômeno para ser consciente de... Mas ela não modifica esse fenômeno.

Sartre vai considerar a imagem como consciência de imagem, porque, para o filósofo, só existem dois tipo de existência: "a existência como coisa do mundo e a existência como consciência" (SARTRE, 2008, p. 108). O problema é que se colocarmos a imagem como fenômeno da consciência, a imagem aparecendo à consciência ou como coisa do mundo, a imagem se torna independe da consciência, como o Em-si existe independente do Para-si, já que, como dito, o Para-si não move ou modifica o Em-si. A imagem se torna coisa do mundo; e se tornando coisa do mundo, como haveria consciência imagética, como posicionar uma lembrança, uma imagem? Isso não seria possível, pois a imagem existiria segundo as leis que lhe são próprias e não segundo a lei da consciência. Ou seja, "dar à imagem um conteúdo sensível é fazer dela uma coisa que obedece às leis das coisas e não às da consciência: retirase assim do espírito qualquer possibilidade de distingui-la das outras coisas do mundo" (SARTRE, 2008, p.110).

Devido algumas questões postas aqui, para Sartre, toda consciência é intencional, e imagem é também intencional. O filósofo conclui que a imagem é uma espécie de consciência, ou seja, "a imagem é um ato e não uma coisa. A imagem é consciência de alguma coisa" (SARTRE, 2008, p. 137). Mas, o problema persiste: se a imagem é consciência de alguma coisa, se, por exemplo, o imaginar de uma maçã é consciência de maçã, onde, mesmo assim, se encontrava essa "maçã" que permite a consciência de maçã? Não estaria essa maçã sendo objeto da consciência imagética ou consciência imaginante? Poderíamos dizer que não, pois ao formular a idéia para saber onde se encontrava a tal "maçã" para que seja uma consciência de maçã, é realizar uma abstração da consciência imagética, pois a "maçã" já é a própria consciência de maçã. Não existe uma imagem "maçã", para depois aparecer a consciência de maçã, a "maça" e a consciência surgem ao mesmo tempo, contemporaneamente, já que toda consciência é consciência de alguma coisa. Logo, a pergunta que fica, então, é como surge a consciência de maçã?

Na obra "O imaginário", Sartre deixa claro que a consciência que ele trata é aquela que se deferência um pouco da maneira comum. O filósofo não usará o termo "consciência", aqui, para mencionar um conjunto de estruturas psíquicas. $\mathrm{O}$ que ele procura referir como consciência serão as particularidades dessas estruturas e assim falaremos da consciência de imagem ou consciência imaginante, consciência perceptiva etc. (SARTRE, 1996).

Aqui parece que entramos em um ponto importante da nossa pesquisa. Sartre parece afirmar que a consciência pré-reflexiva visa objeto, não somente a consciência reflexiva visa um objeto, na intencionalidade. Por exemplo, "a consciência imaginante da árvore visa uma árvore, isto é, um corpo que por natureza é exterior à consciência; ela sai de si mesma, ela se transcende" (SARTRE, 1996, p. 25).

Dessa forma, para que se possa descrever essa consciência, que é a consciência imaginante, é preciso outra consciência: a consciência reflexiva, que torna condição para que a consciência imaginante se volte como um objeto da consciência reflexiva / conhecimento. Mas, Sartre salienta que é preciso tomar cuidado, pois toda consciência é consciência plena, senão, entraríamos em uma contradição, como uma espécie de consciência-inconsciente, o que é um absurdo para o filósofo: "se a consciência imaginante da árvore, por exemplo, não fosse consciência senão a título de objeto da reflexão, resultaria que ela seria, no estado irrefletido, inconsciente de si mesma, o que é uma contradição" (SARTRE, 1996, p. 25). A consciência imaginante, mesmo irrefletida, ainda é consciência e por isso é preciso que ela abrigue uma certa consciência de si mesma. Ou, como afirma Sartre, que ela possua uma consciência não-tética (SARTRE, 1996). Assim, fica claro que Sartre distingue consciência de 
conhecimento, nem toda consciência é conhecimento, mas condição para que o conhecimento surja.

Sartre, então, se vê na necessidade de melhor descrever a consciência imaginante, que é uma consciência não-tética, que está no campo do irrefletido ou do pré-reflexivo. Por isso, o filósofo vai colocar uma questão: como a consciência irrefletida coloca seu objeto e como essa consciência aparece para si mesma na consciência não-tética que acompanha a posição do objeto? (SARTRE, 1996).

O que acontece é que não é só a consciência reflexiva que coloca seu objeto, que é intencional, a consciência pré-reflexiva também é intencional e visa seu objeto. Toda consciência é consciência de alguma coisa. Ou seja, "toda consciência coloca seu objeto, mas cada uma à sua maneira. A percepção, por exemplo, coloca seu objeto como existente. A imagem contém, do mesmo modo, um ato de crença ou um ato posicional" (SARTRE, 1996, p. 26). Esse ponto nos interessa muito, porque aqui Sartre deixa claro o funcionamento da consciência imaginante e respondendo como se tem uma imagem, uma lembrança sem a necessidade de resgatar algo alocado na psique. A consciência se posiciona sempre, ao invés de existir um resgate de uma imagem no inconsciente, por exemplo. O que acontece são posicionamentos do objeto imaginado ou a consciência imaginativa. E Sartre aprofunda mais:

toda consciência coloca o seu objeto, mas cada uma à sua maneira. A percepção, por exemplo, coloca seu objeto como existente. A imagem contém, do mesmo modo, um ato de crença ou um ato posicional. Esse ato pode tomar quatro, e somente quatro, formas: pode colocar o objeto como inexistente, ou como ausente, ou como existente em outra parte; pode também "neutralizar-se", isto é, não colocar seu objeto como existente (essa suspensão da crença continua a ser um ato posicional) (SARTRE, 1996, p. 26).

Dessa forma, podemos concluir que é por isso que se pode imaginar um Centauro (inexistente), uma pessoa com que se marcou um encontro, mas que não compareceu ao tal encontro (ausente), um amigo distante (existente em outra parte). Assim, o ato posicional é ainda constitutivo da consciência de imagem. A imagem é uma consciência, é uma relação consciência e objeto, se opondo a ideia de que as imagens habitam a consciência, já que a imagem é a própria consciência, a consciência imaginante. Assim, frisando novamente, toda imagem é imagem de alguma coisa. Ou seja, imagem é uma espécie de consciência intencional do objeto. Lembrando-se ainda que a escolha dessas lembranças, recordações ou objetos imaginados, está longe de ser uma escolha banal, pois se dá a partir da situação do sujeito no mundo, já que a liberdade, que é escolha, é situada, e é uma escolha ontológica, já que a consciência imaginante, que é uma consciência não-tética, está no campo do irrefletido ou do pré-reflexivo (SARTRE, 2012).

\section{CONCLUSÃO}

O que acontece é que não é só a consciência reflexiva (conhecimento) que coloca seu objeto, que é intencional; a consciência pré-reflexiva também é intencional e coloca seu objeto. Toda consciência é consciência de alguma coisa. Ou seja, toda consciência coloca seu objeto, mas cada uma à sua maneira. A percepção, por exemplo, coloca seu objeto como existente. A imagem contém, do mesmo modo, um ato de crença ou um ato posicional.

Sartre afirma que o passado não necessita ser posicionado pela consciência reflexiva/conhecimento para ser passado, até porque a consciência estar além daquilo que lhe é dado presentemente. A consciência, então, quando se faz conhecimento se posiciona sempre como consciência-lembrança-de..., ao invés de existir um resgate de uma imagem no 
inconsciente, por exemplo. Como entendido, a consciência pré-reflexiva não é também inconsciente. Para Sartre não faz sentido um inconsciente ou uma locação de imagens como arquivos / gavetas na psique. $\mathrm{O}$ que acontece são posicionamentos do objeto imaginado, a consciência imaginativa. O que já sabemos é que, para Sartre, recordar é posicionar um objeto na reflexão, um objeto pode ser posicional ou não-posicional na consciência reflexiva dentro de uma situação ou projeto existencial, a história do sujeito.

\section{REFERÊNCIAS}

SARTRE, J-P. A Imaginação. Edição 6, Porto Alegre: L\&PM, 2008.

SARTRE, J-P. O Imaginário. Volume 46, São Paulo: Ática, 1996.

SARTRE, J-P. O Ser e O Nada: Ensaio De Ontologia Fenomenológica. Edição 21, Petrópolis: Editora Vozes, 2012. 